\title{
Research on the Development Status and Countermeasures of Grain Industry in Shandong Province
}

\author{
Hua Zhao \\ Shandong Xiehe University \\ Jinan, Shandong, 250000, China
}

\begin{abstract}
This paper, starting with the development of the grain industry in Shandong Province, analyzes the characteristics of the grain industry in Shandong Province in the aspects of industrial distribution, equipment application, scientific and technological innovation. The development mode of Shandong's grain industry cluster is also discussed. According to the actual situation of the grain industry in Shandong, the corresponding countermeasures are put forward in promoting the upgrading of the industry, strengthening the construction of the infrastructure, strengthening the innovation of science and technology, and exploring the sustainable development of the circular economy. It can be used as a model to provide reference for other provinces and cities to develop grain industry.
\end{abstract}

Keywords-Grain industry; Industrial Cluster; industrial structure; technological innovation

Shandong is a large province of grain production and circulation, and has an important strategic position in the national food security. The analysis of the characteristics of the development of the grain industry in Shandong Province, the development model and Countermeasures of the grain industry cluster will help to promote the good and fast development of the grain industry in Shandong province.

\section{THE BASIC SITUATION OF THE GRAIN INDUSTRY IN SHANDONG PROVINCE}

Shandong is a major grain producing area and an important commodity grain base. Wheat, corn and sweet potato are the three main grain crops in Shandong. Summer grain is mainly wheat, and the autumn grain is mainly corn and sweet potato. In addition, there are soybeans, rice, millet, sorghum and other small grain grains[1]. Of the 23 provinces in the country, the total grain output of Shandong is only third of that of Heilongjiang and Henan. The total output of grain in Shandong province exceeded 90 billion jin for the first time in 2012year. So far, grain production in Shandong has exceeded 90 billion jin for six consecutive years. The specific data are shown in Table 1.

TABLE I. 2015-2017 YEAR GRAIN PRODUCTION T ABLE OF SHANDONG PROVINCE

\begin{tabular}{|c|c|c|c|}
\hline $\begin{array}{c}\text { Particular } \\
\text { year }\end{array}$ & $\begin{array}{c}\text { total output } \\
\text { (bj) }\end{array}$ & increment(bj) & $\begin{array}{c}\text { Increase the } \\
\text { percentage(\%) }\end{array}$ \\
\hline 2012 & 902.3 & ----- & ------ \\
\hline 2013 & 905.6 & 3.3 & 0.37 \\
\hline
\end{tabular}

Shandong Province Social Science Planning Project "Shandong grain industry supply side structural reform research", Project No: 17CJJJ17.

\begin{tabular}{|c|c|c|c|}
\hline \multicolumn{4}{|c|}{ Cont. to TABLE I } \\
\hline 2014 & 919.3 & 13.7 & 1.51 \\
\hline 2015 & 942.5 & 23.2 & 2.82 \\
\hline 2016 & 940.1 & -2.4 & -0.25 \\
\hline 2017 & 944.6 & 4.5 & 0.48 \\
\hline
\end{tabular}

From 2012 to 2017year, the trend of grain production in Shandong province is shown in Fig. 1.

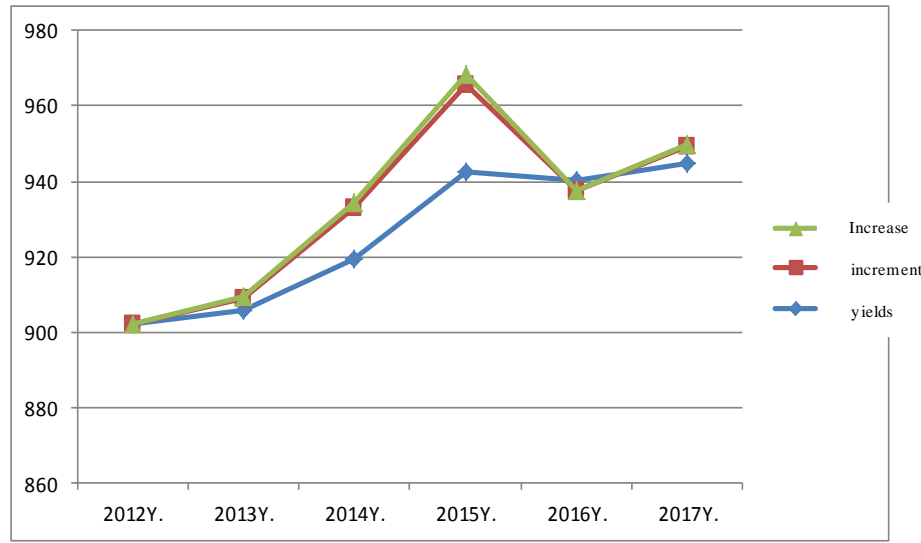

Fig. 1. 2012 to 2017 year Shandong grain yield trend chart

From 2012 to 2017 year, the overall trend of grain production in Shandong Province, for 6 consecutive years, the grain output of Shandong province broke through 90 billion jin, the overall increase trend, a slight decline in 2016year, from 2013 to 2015year, a dramatic increase trend, the 2016-2017 year growth slowed down, but still 450 million Jin increment. In 2017year, the total output of Shandong's grain was 94 billion 460 million jin, and the proportion of grain accounted for $7.64 \%$, ranking third in all provinces and cities in the country.

\section{THE CHARACTERISTICS OF THE GRAIN INDUSTRY IN SHANDONG PROVINCE}

\section{A. The distribution of industries is scattered and can't form scale effect}

Shandong is a large traditional agricultural province, and is the main producing area of grain and northern fruit in China. With the rapid development of industrial economy and modern agriculture, the planting area of vegetables has also increased rapidly, forming the diversified planting structure in Shandong 
now. At present, the main crops in Shandong are as follows: 60 million mu of wheat, 40 million mu of corn, 20 million mu of vegetables, 13 million mu of cotton, 13 million mu of peanuts, 12 million mu of fruit trees, 1 million 700 thousand mu of rice, and 1 million 500 thousand mu of soya bean. The cluster planting of grain varieties were basically formed mainly wheat, corn, sweet potato and peanuts. At the same time, the mode of production is still the small peasant economy of a single family, with a small scale and weak strength. Therefore, in terms of planting technology, farmers unconditionally update processing equipment, improve processing technology, research and development of new products, technology is difficult to upgrade. If we fail to scale up, we will not achieve economies of scale. Shandong has not yet changed the development mode of low level, high consumption and low efficiency.

\section{B. Infrastructure is still weak and technology innovation is not enough}

In recent years, although the investment in agricultural infrastructure at all levels has been increasing, the gap is still large, and some of the farmland water conservancy in the province is more serious. Some new irrigation and water conservancy facilities also have some problems such as low standard of construction and lack of management and protection. There are 112 million mu of cultivated land in the whole province. The dry land area of water without water is about $25000000 \mathrm{mu}$. This part of the land is basically on the sky, while the drought is greatly reduced and even out of production. In addition, agricultural research institutes in Shandong province are scattered. Grain industry related enterprises lack scientific research strength, weak $R$ \& $D$ capability of key technology, and lack of core competitiveness. Scientific research units and industrial enterprises are not closely linked, collaborative innovation is not enough, and the transformation ability of scientific research achievements is weak. Agricultural machinery research and development innovation is not enough, agricultural machinery agronomy fusion degree is relatively low, key links and core technologies need to be breakthroughs. The grass-roots agricultural technology extension team is not perfect, and agricultural technology extension can't be fully accessible to households or to the fields. At present, the rural migrant workers are mostly women and middle aged and old, with low educational level, weak ability to accept new knowledge and new technology, and the key technology of increasing grain production is difficult to be popularized.

\section{The quality of cultivated land is slow and the capacity for sustainable production is weak}

In Shandong province, the soil layer of cultivated land is thin, the cultivation is shallow and the fertility is low. The content of soil organic matter in most farmland is less than $1.2 \%$, and the soil organic matter content of farmland soil in the developed countries of the United States and Europe is generally above $3 \%$. Due to the problems of soil erosion, land desertification, salinization, seawater intrusion and reusing light raising, the quality of cultivated land in Shandong province has been improved slowly, which restricts the improvement of grain production capacity. Extensive production of chemical fertilizers, pesticides and agricultural films has resulted in serious pollution of agricultural non-point sources. The amount of cultivated land in Shandong province is only $5.6 \%$ of the country, but the use of chemical fertilizer accounts for $8 \%$ of the national consumption, the utilization rate of nitrogen fertilizer is only about $30 \%$, and the gap is very large compared with that of the developed countries. The utilization rate of pesticides is less than $30 \%$, which is more than 20 percentage points lower than that of developed countries. Agricultural water consumption is serious. Developed countries generally produce 2 kilograms of grain per cubic meter of irrigation water, and Shanodng province only produces about 1 kilograms.

\section{THE DEVELOPMENT MEASURES OF THE GRAIN INDUSTRY} In SHANDONG PROVINCE

The Shandong Provincial Committee, the provincial government and the relevant departments attach great importance to the economic development of the grain industry, and have issued a series of supporting policies and measures to guarantee the economic development of the grain industry in the whole province. If we want to really develop the grain industry of Shandong Province, we can proceed from the following aspects:

\section{A. Vigorously promote grain industry clusters, achieve industrial transformation and upgrading, quality and efficiency}

The grain industry in Shandong province is scattered and can't achieve the scale effect. If we want to better develop the grain industry in Shandong province, we can start with improving the grain industry cluster. Shandong's grain industry cluster has already had a certain embryonic form and has entered a period of rapid growth. However, the lack of farmers' professional cooperatives and rural land circulation cooperatives has only been implemented in recent years[2], and it is seriously lagging behind the development of the grain industry cluster. Therefore, we must attach great importance to the construction and development of cooperatives and develop leading enterprises in grain industrialization. Support a group of leading enterprises of grain industrialization with obvious demonstration power. We should optimize the allocation of resources through property rights replacement, equity transfer, merger and reorganization, and develop a batch of leading enterprises in grain industrialization. Support qualified leading enterprises to take part in the policy grain purchasing and storage business, and explore leading enterprises to participate in the local grain reserve mechanism. To guide leading enterprises and other new agricultural operators and farmers to build a solid interest linkage mechanism to promote highquality grain cultivation and increase farmers' income.

The prominent characteristics of Shandong's grain industry economy are the large volume of processing and transformation and the strong driving ability of leading enterprises. In recent years, combined with enterprise reform, industrial layout and structural adjustment, we have been guiding the accumulation of production factors to dominant enterprises[3]. In addition, the construction of industrial parks, based on the industrial base and advantages, actively implement the strategy of returning to the suburbs, increase the 
intensity of attracting investment, relying on the leading enterprises, leading the large-scale and intensive processing, vigorously cultivating industrial agglomeration areas, encouraging enterprises to build parks and entering the park, and building a batch of special grain and oil industrial parks. The economic development of the industry of dynamic industry.

\section{B. Strengthening the construction of grain infrastructure and improving the quality of cultivated land}

First, speed up the research and development of new agricultural implements, and intensify the introduction of irrigation and drainage, drought resistant and water-saving irrigation equipment. Focusing on wheat and maize, efforts should be made to popularize mechanical equipment such as farming, planting, harvesting, drying and transportation to highlight corn seed harvesting machinery and equipment. Use the resources of grain storage facilities well. Making full use of the resources of grain storage facilities, developing the existing storage facilities for the existing state-owned grain enterprises in many ways, providing the postpartum service for the new agricultural operators and farmers, providing storage service for the processing enterprises, providing the delivery service for the futures market, and providing the delivery warehouse service for the "Internet + grain" management model. To provide distribution services for urban and rural residents[4].

Second, to strengthen the construction of grain base, the construction of grain base has played a powerful role in expanding the advantages of regional resources, enhancing the function of scientific and technological service, improving the comprehensive agricultural production capacity, cultivating the strength of agricultural development, and promoting the transformation of the rural product economy to the commodity economy and the market economy.

Third, to carry out the action of improving the quality of cultivated land, the implementation of soil improvement and restoration, pesticide residue treatment, the prevention and control of film pollution, the comprehensive utilization of straw, the treatment of livestock and poultry manure, the remediation of heavy metal pollution and so on. At the same time, the reform of the middle and low yield fields, the treatment of saline alkali land, the waste land, the abandoned land, and the idle land reclamation and reclamation are carried out.

\section{Strengthening the innovation of grain science and technology and implementing the development of agriculture by science and technology}

To accelerate the innovation of grain science and technology and cultivate innovative grain leading enterprises, we can study the fields of nutrition and health, quality and safety, grain saving, processing and transformation, modern logistics, and "intelligent food". Development and application of high-efficiency grain save and energy saving complete grain and oil processing equipment, and carry out application demonstration of Intelligent Grain factory, intelligent storage, intelligent drying and so on. We should encourage scientific research institutions and universities to focus on the needs of enterprises, and promote scientific and technological innovations such as information, biology and new materials through the joint establishment of R \& D funds, laboratories, and work stations[5]. To strengthen the comparison of technical standards for inspection of grain quality at home and abroad and unqualified grain treatment technology, and to carry out technical trade measures and related research on import and export grain inspection and quarantine.

In addition, speed up the transformation of scientific and technological achievements. We should implement the "science and technology grain revitalization project", set up an information service platform for the transformation of scientific and technological achievements, and promote the industrialization of scientific and technological achievements. We should play the role of national engineering laboratories, key laboratories and academician workstations in the grain field, and strengthen the construction of the integration demonstration base of grain scientific and technological achievements and the cooperative innovation community of science and technology. Relying on the national food industry science and technology innovation alliance, we will promote the opening and sharing of scientific and technological resources.

\section{Exploring circular economy and speeding up the transformation of new and old energy in grain industry}

First of all, according to the idea of "layout optimization, industry chain, enterprise cluster, material circulation, innovation management, intensive development", we should pay attention to the integration of upstream and downstream products, promote the integration of the 123 industries, support enterprises to carry out efficient utilization of raw materials, product echelon development, and energy cycle utilization, and explore the development of circular economy[6]. Actively adapt to the new normal economic development, relying on scientific and technological forces to promote industrial transformation and upgrading and the conversion of new and old kinetic energy, support enterprises to increase technological transformation, integration of production, research and research, innovation platform construction investment.

Secondly, develop the whole industrial chain, promote the integration of the 123 industries, and support the grain enterprises to enhance the value chain with the whole industrial chain. The new agricultural operation main body is butted to the upstream with the directional input and special service, and the logistics marketing and service network are extended to the lower reaches, and the grain source base, the processing scale, the product quality and the service diversification are realized, and the green and organic food supply chain is put forward. We should carry out information monitoring, analysis and early warning in the whole industry chain, and guide grain production and marketing balance[7].

Third, the development of new formats, the implementation of the "Internet +" action, promote the sharing and opening of grain related data, the development of food public service platform, the promotion of "online stores", "experience store" and other retail formats, to promote the integration of online and offline. Relying on the national grain electronic trading platform, expand logistics and transportation, financial services and other functions. The development and utilization of grain 
culture resources, supporting the construction of grain saving and food propaganda and education bases and cultural venues, guiding the grain industry to increase tourism functions, and develop new forms of leisure, sightseeing, experiential consumption and so on.

\section{E. Strengthening the government's guarantee}

The grain industry in Shandong should take the grain industry as an important content to ensure the food security, and to promote the structural reform of the grain supply side, adhere to the advance of the science and technology, accelerate the transformation of the new and old kinetic energy, cultivate the whole industry chain management mode, promote the integration and development of the 123 industry, and realize the transformation of the grain industry. Upgrade, improve quality and increase efficiency. The following can be taken as follows:

First, increase financial and tax support. Make full use of the existing funding channels, support grain storage and logistics facilities, national modern grain industry development demonstration park (base) construction and grain industry transformation and upgrading. We should support the development of grain industry by making full use of the reward funds of large grain producing provinces, grain producing and oil producing large county awards, grain risk funds and local matching withdrawal funds. We should give full play to the guiding function of financial funds and actively guide financial capital and social capital to increase investment in the grain industry. The purchase of warehousing and drying equipment by new agricultural operators can enjoy subsidies for agricultural machinery purchase according to regulations. Strictly implement the enterprise's research and development, expenses plus Deduction Policy. To implement the relevant policies of the grain processing enterprises that are exempt from the enterprise income tax policy and the state added value tax rate according to the regulations.

Second, improve the policy of financial and insurance support. The policy and commercial financial institutions should provide financial services for grain purchase, processing, storage, logistics and other links under the premise of risk control, and increase credit support to the grain industry development and the key leading enterprises of agricultural industrialization. We should establish and improve the financing guarantee mechanism of the credit guarantee fund for grain purchase loans, and reduce the risk of bank credit. Support grain enterprises to raise funds through issuing shortterm financing bonds and other non-financial corporate debt financing tools. Under the premise of preventing the risk, we should actively carry out the financing business of the enterprise building mortgage, the deposit slip, the order, the account receivable pledge and so on, and innovate the service mode such as "credit + insurance", industry chain finance and so on.

\section{CONCLUSION}

Shandong province is a major province of grain production. It is the main grain producing province and important commodity grain supply base in China. Grain is an important strategic material for the stability of the world. It is the basis of the development of the national economy and the guarantee of national security. It is of great significance to speed up the transformation and upgrade of the grain industry, improve the ability of comprehensive grain production and the ability of sustainable development, to achieve the goal of building a well-off society in an all-round way, to build a harmonious socialist society and to ensure the sustained and healthy development of the national economy.

\section{REFERENCES}

[1] Zhao Yuxin. The symbol and path choice of grain industry development mode transformation. Rural economy,2013(8):51-54.

[2] Li Anmo. The only way for grain professional cooperatives to develop grain industry. Research on grain problem,2014(4):39-41.

[3] Li Tongshan. On the basic princip les of changing the development mode of the grain industry. Journal of Heilongjiang Grain, 2016(12):22-26.

[4] Wu Zhengguang, Li De, Ye Jing. Investigation on the development of grain industry in Jiangsu Province.China's Grain Economy,2018(04):7680.

[5] Liu Hui. The extensive development of the grain industry is changing-Science and technology rejuvenate grain. Rural areas, agriculture and farmers (A Edition). 2016(12):53-57.

[6] Yan Bo, Hu Wenguo. Research on the strategy of grain industry economic development. China's Grain Economy,2017(12):34-39.

[7] Fu Hemin, Qi Jianxiang, The "China Green Model" promotes the sustainable development of the grain industry. Hunan Agriculture, 2016(12):41-45. 